\title{
Pharmacological Advances in the Treatment of Alzheimer's Disease
}

\author{
José Guedes da Silva junior* \\ Bruno Diógenes Cecílio Sá, Talyta Valéria Siqueira do Monte, Brazil
}

*Corresponding author: José Guedes da Silva Júnior, Bruno Diógenes Cecílio Sá, Talyta Valéria Siqueira do Monte, Brazil

\section{Introduction}

Alzheimer's disease is a disease that is associated with an increase in beta-amyloid peptide that accumulates in amyloid plaques found in multiple areas of the brain, such as the cerebral cortex, hippocampus, basal ganglia, thalamus, and cerebellum. One of the major genetic risks for the development of this disease is associated with the malfunction of Apoliprotein E (Apo-E), a protein whose performance ultimately causes the degradation of Beta amyloid. This neurodegenerative disease is an increasingly common problem due to the increasing aging of the world population and estimates are tripling by 2050 the number of people with Alzheimer's in the world. Treatment-approved drugs only alleviate symptoms that worsen with evolution and no effective treatment is currently found [1-3]. The drug exendin-4 (exenatide) used to treat type 2 diabetes has shown decreased levels of hippocampal IRS-1 (IRS-1pSer) serine phosphorylation and activated JNK (c-Jun N-terminal kinases) resulting in a protective effect on mouse neurons reversing brain damage and improving cognitive behavioral measures. The drug bexarotene used to treat skin cancer reduced the beta-amyloid protein plaque area in the mice brain by more than $50 \%$ within 72 hours and stimulated the rapid reversal of cognitive, social and olfactory deficits and improved the function of the mouse. neural circuit, besides stimulating the production of APO-E that was able to dissolve the plaques that carry the symptoms of the disease. A study of ouabain hormone used in the treatment of cardiovascular disease has shown a protective effect on mouse neurons suggesting a new possibility to develop drugs that block the processes linked to neuronal death. Thus we can conclude that the efficacy of these drugs must first be confirmed in human studies since mouse tests often do not repeat in humans.

\section{References}

1. Paige E Cramer, John R Cirrito, Daniel W Wesson, C Y Daniel Lee, J Colleen Karlo, et al. (2012) ApoE-Directed Therapeutics Rapidly Clear ü-Amyloid and Reverse Deficits in AD Mouse Models.

2. Theresa R Bomfim, Leticia Forny Germano, Luciana B Sathler, Jordano Brito Moreira, Jean Christophe Houzel, et al. (2012) An anti-diabetes agent protects the mouse brain from defective insulin signaling caused by Alzheimer's disease- associated A $\beta$ oligomers. The Journal of Clinical Investigation 122(4): 1339-1353.

3. Giorgio Aicardi (2013) New Hope from an Old Drug: Fighting Alzheimer's Disease with the Cancer Drug Bexarotene (Targretin)? Rejuvenation Research (16)6: 524-528.

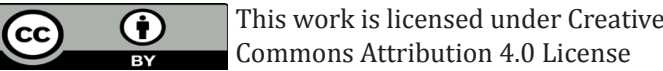

To Submit Your Article Click Here: Submit Article

DOI: $10.32474 /$ GJAPM.2019.02.000127

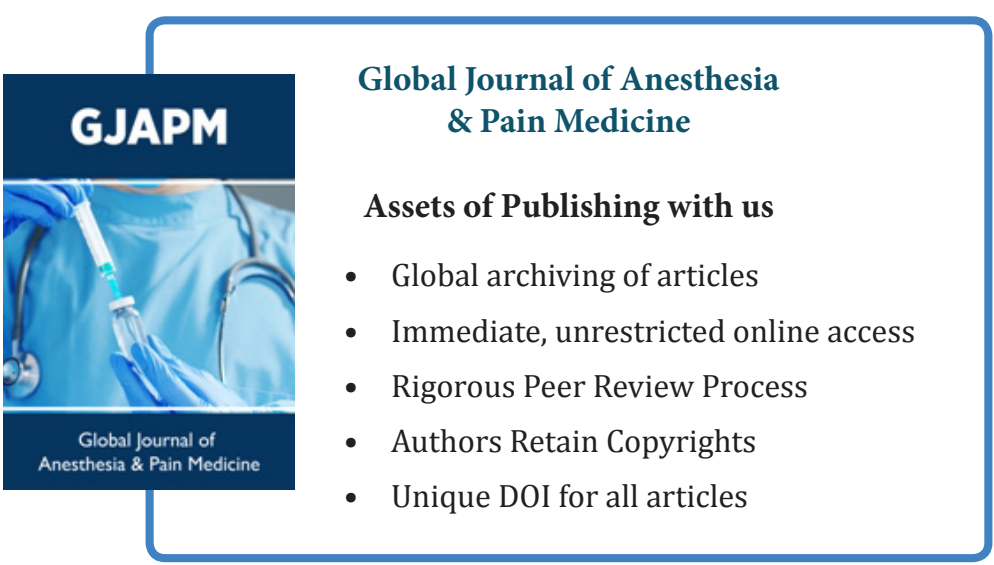

